\title{
A quantum chemical insight into corrosion inhibition effects of moxifloxacin and betamethasone drugs
}

\author{
G. Gece ${ }^{1}$ and S. Bilgiç ${ }^{2} *$ \\ ${ }^{1}$ Bursa Tecnical University Department of Chemistry Faculty of Engineering and Natural \\ Sciences, 16310 Yildirim Bursa, Turkey \\ ${ }^{2}$ Ankara University Faculty of Science, Department of Physical Chemistry, 06100 Beşevler \\ Ankara, Turkey \\ *E-mail: semra.bilgic@science.ankara.edu.tr
}

\begin{abstract}
The corrosion protection properties of several drugs attract too much attention in recent years due to the structural closeness they share with effective corrosion inhibitors. It is obvious that the mainstay for the choice of drugs as corrosion inhibitors is mostly due to their environmentally friendly nature. In parallel, interest in the use of expired drugs has also seen a resurgence in corrosion research community. However, there still exists much skepticism about the value such usage can add to corrosion inhibition of metals. In this regard, in a previous study, two expired drugs, i.e., moxifloxacin and betamethasone (betnesol), which are widely used for the systemic treatment of bacterial infections and inflammation respectively, have been experimentally investigated as effective corrosion inhibitors for aluminum in sulfuric acid solution. According to the experimental findings, an increase in inhibitor concentration resulted in an increase of the inhibition efficiency of the inhibitors and transfer resistance. The anodic type nature of moxifloxacin and betamethasone has also been illustrated by polarization curve, and from a thermodynamical aspect, both chemisorption and physisorption of these drugs on aluminum metal surface have been proposed. However, very little is known about the relation between molecular structure/electronic properties and inhibition efficiencies of these compounds at the atomic level. For this purpose, the structures and the ground-state energies of moxifloxacin and betamethasone have been analyzed employing density functional theory (DFT) calculations. The reported optimized geometries, molecular properties such as highest occupied molecular orbital energy $\left(E_{\mathrm{HOMO}}\right)$, the lowest unoccupied molecular orbital energy $\left(E_{\mathrm{LUMO}}\right)$ and the energy gap $(\Delta E)$ as well as essential global reactivity parameters have also been used to reveal the inhibition efficiency of moxifloxacin and betamethasone. The experimental data which suggest better inhibition by betamethasone have been theoretically acknowledged.
\end{abstract}

Keywords: corrosion, inhibitor, aluminum, moxifloxacin, betamethasone, quantum chemical calculations.

Received: November 5, 2018. Published: December 19, 2018

doi: $\underline{10.17675 / 2305-6894-2018-7-4-16}$ 


\section{Introduction}

Structural components made from aluminum are vital to the aerospace industry and very important in other areas of transportation and building in which light weight, durability, and strength are needed. However, aluminum and its alloys are readily attacked in dilute nitric, sulfuric, or hydrochloric acid solutions [1,2]. It has been reported that the dissolution rate of aluminum in sulfuric acid becomes appreciable between $50 \%$ and $100 \%$ concentration, with the maximum rate occurring at 70-90\% concentration [3]. Different organic molecules are used for aluminum corrosion, and the active ingredients of these inhibitors invariably contain one or more functional groups containing one or more heteroatoms, through which the inhibitors anchor onto the metal surface [4]. Since the substructures of drugs and corrosion inhibitors share so many similarities, the use of drugs as corrosion inhibitors is an active field of research [5].

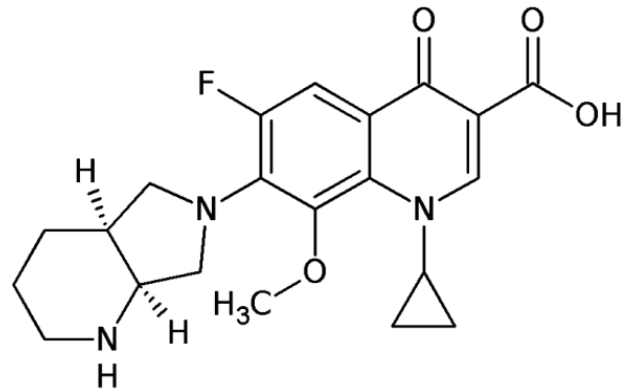

(a)

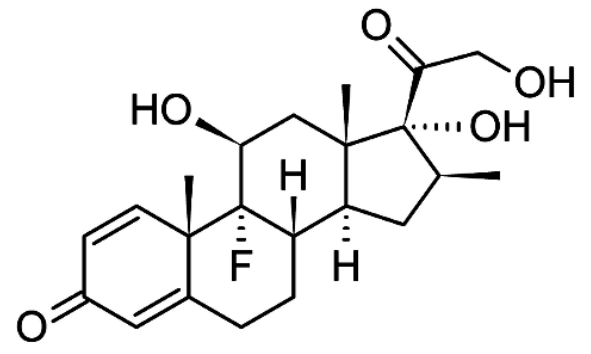

(b)

Figure 1. Molecular structure of (a) moxifloxacin and (b) betamethasone.

Two expired drugs, i.e., moxifloxacin and betamethasone (Figure 1) have been reported as effective corrosion inhibitors for aluminum in sulfuric acid solution in a recent experimental study by Nathiya et al. [6]. They showed that in the presence of these two expired drugs, the corrosion rate of aluminum in $1 \mathrm{M} \mathrm{H}_{2} \mathrm{SO}_{4}$ solution was significantly decreased. The minimum corrosion rate was observed at $400 \mathrm{ppm}$ concentration of the drugs by all experimental methods, i.e., weight loss, potentiodynamic polarization, and electrochemical impedance measurements. The inhibition efficiency (IE) of betamethasone was found to be a little higher ( 95\%) than that of moxifloxacin $(\sim 86 \%)$, and this difference was explained in terms of extra $-\mathrm{OH}$ groups with the aromatic ring that betamethasone possesses.

The corrosion inhibition efficiencies of these drugs have been slurred over at the aforementioned experimental study, and a deep understanding of the inhibition properties still has not been fully cleared up. The advancements in computer simulation techniques hold promise that questions regarding the inhibitive properties of such compounds can be addressed at the atomic level [7-10]. Thus, in this study we attempted to elucidate the origin of the inhibition properties of moxifloxacin and betamethasone by using density 
functional theory (DFT) method which has proven to be a very efficient method for the prediction of different molecular properties.

\section{Computational}

All calculations of two drugs were carried out employing a DFT method as implemented in Gaussian09 [11]. The exchange-correlation functional, M06-2X [12] was selected due to its good performance on ionization potentials and electron affinities, as well as dispersionlike interactions. In addition, the double-zeta basis set, DGDZVP [13], was applied in order to include an all-electron description of the different atoms present in the studied compounds. The gas-phase optimized geometries were obtained with the level of theory, M06-2X/DGDZVP. These structures were reoptimized in the presence of water as implicit solvent, in this case, the continuum solvation model SMD was used [14]. In the process of geometry optimization for the fully relaxed method, convergence of all the calculations and the absence of imaginary values in the wave numbers confirmed the attainment of local minima on the potential energy surface. The effects of the frontier molecular orbital energies, their differences, and some reactivity parameters were investigated.

\section{Results and Discussion}

The best start-point to correlate the molecular structure and corrosion inhibition properties of the drugs is by knowing their electronic structure. In fact, the study of the electronic structure and related properties is an unavoidable requisite to explain at molecular level the mechanisms of these compounds. Betamethasone is a glucocorticoid, which promotes the conversion of protein into glucose and glycogen, acts as an anti-inflammatory and blocks the immune response [15]. On the other hand, quinolones containing a fluorine substituent were developed as better gyrase-targeting antibiotics than the non-fluorinated quinolone, and moxifloxacin is a new generation and most widely known one which was introduced in 2000 [16]. The most significant activities of such drugs are due to some structural conditions as shown in Figure $2[17,18]$.

The inhibition effects of compounds used as corrosion inhibitors are generally associated with adsorption of molecules onto a metal surface [7]. In the case of chemical adsorption, the adsorption energy of a molecule is controlled by the balance donating (the highest occupied molecular orbital - HOMO) and back-donating (the lowest unoccupied molecular orbital - LUMO) interaction terms. The strength of the interaction is directly related to the HOMO-LUMO energy separation. Thus, of the two HOMO-LUMO interactions which are in general possible, it is the one between the HOMO of the donor and LUMO of the acceptor which will tend to dominate. In general, the smaller the HOMO-LUMO separation, the stronger the interaction. Organic molecules with less negative HOMO values are expected to have high donation ability and therefore high inhibition efficiency. The LUMO energy is another significant reactivity parameter which is related to the electron affinity and characterizes the capacity of a molecule to gain 
electron from a metal. The lower the value of the LUMO energy, the stronger the electron accepting ability of the molecule.

(a)

Direct interaction with DNA gyrase, and increases anti-anaerobic activity

(b)
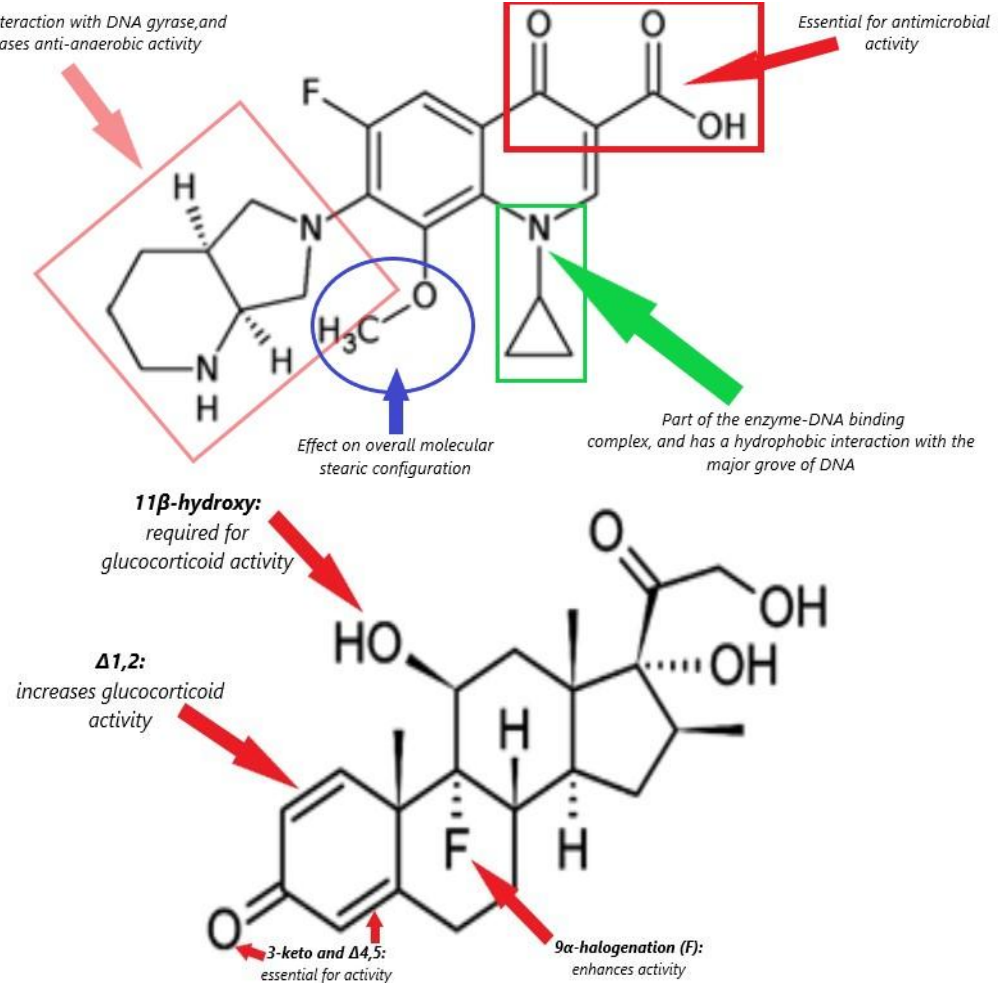

Figure 2. Commonly accepted structure-activity relationship for (a) moxifloxacin and (b) betamethasone structures according to current knowledge.

The chemical potential, $\mu$, and the hardness, $\eta$, are the first and second derivatives, respectively, of the energy with respect to the number of electrons when the external potential relative to the electron cloud is constant. In addition, $\mu$ can be related to the electronegativity, $\chi$, of the system. Global properties can be obtained by the frontier molecular orbital energies according to Koopmans theorem. The ionization potential $(I)$ and electron affinity $(A)$ are given by $I=-E_{\mathrm{HOMO}}$ and $A=-E_{\mathrm{LUMO}}$. In numerical applications, chemical potential $\mu$ and hardness $\eta$ are expressed on the basis of finite difference approximations in terms of the ionization potential $I$ and the electron affinity $A$; $-\mu=\frac{1}{2}(I+A)=\chi$ and $\eta=\frac{1}{2}(I-A)$, where $\mu$ is the chemical potential and $\chi$ is the electronegativity. The electrophilicity is a descriptor of reactivity that allows a quantitative classification of the global electrophilic nature of a molecule within a relative scale and is effectively the power of a system to soak up electrons. The electrophilicity index $\omega$ can be expressed by $\omega=\mu^{2} / 2 \eta$ and the global softness is defined as $S=(2 \eta)^{-1}=1 /(I-A)$.

Based on these explanations, it would be appropriate to compare the electronic properties of moxifloxacin and betamethasone molecules. For this purpose, the quantum 
chemical parameters of these compounds related to molecular electronic structure and reactivity such as $E_{\mathrm{HOMO}}, E_{\mathrm{LUMO}}$ and $\Delta E=E_{\mathrm{LUMO}}-E_{\mathrm{HOMO}}$ are compared in Table 1.

Table 1. Quantum chemical parameters of the neutral structures of the compounds studied.

\begin{tabular}{|c|c|c|c|}
\hline Parameters & Phase $^{\text {b }}$ & Betamethasone & Moxifloxacin \\
\hline $\operatorname{IE}(\%)^{\mathrm{a}}$ & & 95.40 & 85.01 \\
\hline \multirow[t]{2}{*}{$E_{\mathrm{HOMO}}(\mathrm{eV})$} & G & -8.599 & -7.429 \\
\hline & A & -8.531 & -7.290 \\
\hline \multirow[t]{2}{*}{$E_{\mathrm{LUMO}}(\mathrm{eV})$} & G & -0.792 & -0.658 \\
\hline & A & -1.035 & -0.866 \\
\hline \multirow[t]{2}{*}{$\Delta E\left(E_{\mathrm{L}}-E_{\mathrm{H}}\right)(\mathrm{eV})$} & G & 7.807 & 6.771 \\
\hline & A & 7.496 & 6.424 \\
\hline \multirow[t]{2}{*}{$\omega$} & G & 2.823 & 2.415 \\
\hline & A & 3.052 & 2.589 \\
\hline \multirow[t]{2}{*}{$\chi$} & G & 4.695 & 4.044 \\
\hline & A & 4.783 & 4.078 \\
\hline \multirow[t]{2}{*}{$\eta$} & G & 3.904 & 3.386 \\
\hline & A & 3.748 & 3.212 \\
\hline \multirow[t]{2}{*}{$S$} & G & 0.128 & 0.148 \\
\hline & A & 0.133 & 0.156 \\
\hline
\end{tabular}

${ }^{\mathrm{a}}$ Ref. [6]. ${ }^{\mathrm{b}} \mathrm{G}$, gas phase $(\varepsilon=1.0)$; A, aqueous phase $(\varepsilon=78.5)$.

When the results in Table 1 are examined, it is seen that the highest HOMO energy and the lowest LUMO energy and $\Delta E$ values are found for moxifloxacin in both phases, contrary to the expectations. In other words, no correlation could be found between the calculated data and those experimental parameters that attest to betamethasone with high inhibition efficiency. It should be noted here that these calculations belong to the neutral structure of the inhibitors. However, in a strong acidic environment in which the experimental study was carried out, that both an alcohol compound, betamethasone and moxifloxacin exist in protonated form (Figure 3) as demonstrated by other researchers [19].

Considering this unassailable effect of low $\mathrm{pH}$ on the structures of the inhibitors, the calculations are also made for the protonated forms of both compounds and the results are given in Table 2. 

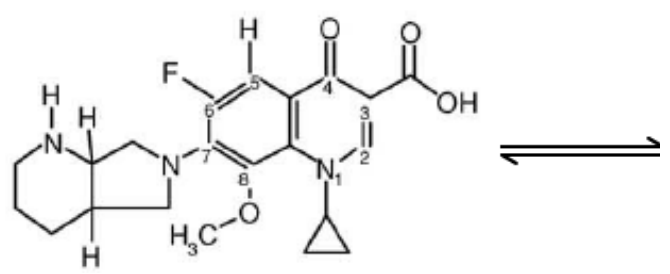<smiles>COc1c(N2CC3[NH+]CCC[C@@H]3C2)c(F)cc2c(=O)c(C(=O)O)nn(C3CC3)c12</smiles><smiles>CC1CC2C3(CCC4=CC(=O)C=CC43C)CC(O)CC2(C)[C@]1(O)C(=O)CO</smiles>
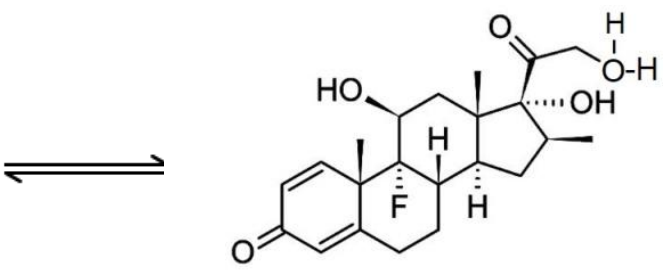

Figure 3. Protonation equilibria of moxifloxacin and betamethasone.

Table 2. Quantum chemical parameters of the protonated structures of the compounds studied.

\begin{tabular}{cccc}
\hline Parameters & Phase $^{\mathbf{b}}$ & Betamethasone & Moxifloxacin \\
\hline${\text { IE }(\%)^{\mathrm{a}}}_{E_{\mathrm{HOMO}}(\mathrm{eV})}$ & $\mathrm{G}$ & 95.40 & 85.01 \\
$E_{\mathrm{LUMO}}(\mathrm{eV})$ & $\mathrm{A}$ & -10.523 & -9.602 \\
& $\mathrm{G}$ & -6.942 & -7.513 \\
$\Delta E\left(E_{\mathrm{L}}-E_{\mathrm{H}}\right)(\mathrm{eV})$ & $\mathrm{A}$ & -5.614 & -2.991 \\
& $\mathrm{G}$ & -2.753 & -0.929 \\
$\omega$ & $\mathrm{A}$ & 4.909 & 6.611 \\
& $\mathrm{G}$ & 4.189 & 6.584 \\
$\chi$ & $\mathrm{A}$ & 13.263 & 5.998 \\
& $\mathrm{G}$ & 5.611 & 2.706 \\
& $\mathrm{~A}$ & 8.069 & 6.297 \\
& $\mathrm{G}$ & 4.848 & 4.221 \\
& $\mathrm{~A}$ & 2.455 & 3.306 \\
& $\mathrm{G}$ & 2.095 & 3.292 \\
& $\mathrm{~A}$ & 0.204 & 0.151 \\
& & 0.239 & 0.152 \\
\hline
\end{tabular}

${ }^{\mathrm{a}}$ Ref. [6]. ${ }^{\mathrm{b}} \mathrm{G}$, gas phase $(\varepsilon=1.0)$; A, aqueous phase $(\varepsilon=78.5)$. 
When the results of the protonated structures in Table 2 were evaluated, although the

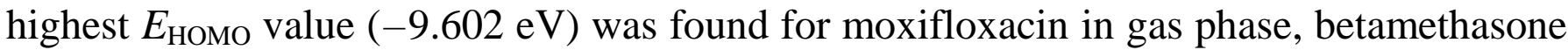
molecule has the lowest $E_{\mathrm{LUMO}}$ and $\Delta E$ values. Not only that, the highest $E_{\mathrm{HOMO}}(-6.942 \mathrm{eV})$ and the lowest $E_{\text {Lumo }}(-2.753 \mathrm{eV})$ and $\Delta E(4.189 \mathrm{eV})$ values are also found for betamethasone in the aqueous phase. A more reactive nucleophile is characterized by a lower value of $\omega$, in opposite a good electrophile is characterized by a high value of $\omega$. In this regard, betamethasone is a good electrophile. A hard molecule has a large energy disparity and a soft molecule has a small energy disparity. Soft molecules are more reactive than hard ones because they could easily offer electrons to an acceptor. As is seen, betamethasone is softer than moxifloxacin. Hereby, the comparison of chemical hardness values also shows a similar trend to those of the energy gaps, being betamethasone the lowest. The obtained values for $E_{\mathrm{HOMO}}, E_{\mathrm{LUMO}}$ and $\Delta E$ as well as other parameters explicitly confirm that, as an corrosion inhibitor for aluminum in acidic media, it is possible to achieve better corrosion inhibition performance with betamethasone compared to moxifloxacin, as indicated by the experimental findings.

\section{Conclusions}

As a result, a correlation could be established by the density functional theory approach between the parameters related to the electronic structures of the two out-of-use drugs, namely betamethasone and the moxifloxacin molecules, and their ability to prevent corrosion. Calculations in the theory level of M06-2X/DGDZVP used in this study confirmed that betamethasone is superior to moxifloxacin in hindering the corrosion of aluminum in an acidic environment in a way that supports experimental data. For the protonated forms of the studied inhibitors, the concordance between the parameters of the global reactivity obtained in both the gas and the aqueous phase and the electronic parameters supported the findings.

\section{References}

1. E. Ghali, Corrosion Resistance of Aluminum and Magnesium Alloys: Understanding, Performance, and Testing, John Wiley \& Sons, Inc., Hoboken, New Jersey, 2010.

2. R.B. Mears, in Corrosion Handbook, ed. H.H. Uhlig, Wiley, Hoboken, New Jersey, 1976, p. 39.

3. ASM Specialty Handbook Committee, Corrosion of Aluminum and Aluminum Alloys, ASM International, Materials Park, Ohio, 1999, p. 313.

4. K. Xhanari and M. Finšgar, Arab. J. Chem., 2016, doi: 10.1016/j.arabjc.2016.08.009

5. G. Gece, Corros. Sci., 2011, 53, 3873. doi: 10.1016/j.corsci.2011.08.006

6. R.S. Nathiya, S. Perumal, V. Murugesan and V. Raj, J. Bio. Tribo. Corros., 2018, 4, 1. doi: $10.1007 / \mathrm{s} 40735-017-0120-1$

7. G. Gece, Corros. Sci., 2008, 50, 2981. doi: 10.1016/j.corsci.2008.08.043 
8. G. Gece and S. Bilgiç, Int. J. Corros. Scale Inhib., 2017, 6, 476. doi: 10.17675/23056894-2017-6-4-7

9. A.K. Oyebamiji and B.B. Adeleke, Int. J. Corros. Scale Inhib., 2018, 7, 498. doi: 10.17675/2305-6894-2018-7-4-2

10. M. Shahraki， S.M. Habibi-Khorassani， M. Noroozifar，Z. Yavari， M. Darijani and M. Dehdab, Iran. J. Mater. Sci. Eng., 2017, 14, 35. doi: 10.22068/ijmse.14.4.35

11. M.J. Frisch, G.W. Trucks, H.B. Schlegel, G.E. Scuseria, M.A. Robb, J.R. Cheeseman, G. Scalmani, V. Barone, B. Mennucci, G.A. Petersson, H. Nakatsuji, M. Caricato, X. Li, H.P. Hratchian, A.F. Izmaylov， J. Bloino， G. Zheng, J.L. Sonnenberg, M. Hada, M. Ehara， K. Toyota， R. Fukuda， J. Hasegawa， M. Ishida， T. Nakajima， Y. Honda, O. Kitao, H. Nakai, T. Vreven, J.A. Montgomery, Jr., J.E. Peralta, F. Ogliaro, M. Bearpark， J.J. Heyd， E. Brothers， K.N. Kudin， V.N. Staroverov， R. Kobayashi, J. Normand, K. Raghavachari, A. Rendell, J.C. Burant, S.S. Iyengar, J. Tomasi, M. Cossi， N. Rega， J.M. Millam， M. Klene， J.E. Knox， J.B. Cross， V. Bakken, C. Adamo, J. Jaramillo, R. Gomperts, R.E. Stratmann, O. Yazyev, A.J. Austin, R. Cammi，C. Pomelli，J.W. Ochterski，R.L. Martin，K. Morokuma，V.G. Zakrzewski, G.A. Voth, P. Salvador, J.J. Dannenberg, S. Dapprich, A.D. Daniels, Ö. Farkas, J.B. Foresman, J.V. Ortiz, J. Cioslowski and D.J. Fox, Gaussian 09, Revision C.01, Gaussian, Inc., Wallingford CT, 2009.

12. Y. Zhao and D. G. Truhlar, Theor. Chem. Acc., 2008, 120, 215.

13. N. Godbout, D.R. Salahub, J. Andzelm and E. Wimmer, Can. J. Chem., 1992, 70, 560.

14. A.V. Marenich, C.J. Cramer and D.G. Truhlar, J. Phys. Chem. B, 2009, 113, 6378.

15. C. Kubli-Garfias and R. Vázquez-Ramírez, J. Mol. Struct., 1998, 454, 267. doi: 10.1016/S0166-1280(98)00296-6

16. L. Riaz, T. Mahmood, A. Khalid, A. Rashid, M.B.A. Siddique, A. Kamal and M.S. Coyne, Chemosphere, 2018, 191, 704. doi: 10.1016/j.chemosphere.2017.10.092

17. P. Buchwald and N. Bodor, Pharmazie, 2004, 59, 396.

18. L.R. Peterson, Clin. Infect. Dis., 2001, 33, S180. doi: $10.1086 / 321846$

19. M.H. Langlois, M. Montagut, J.P. Dubost, J. Grellet and M.C. Saux, J. Pharm. Biomed. Anal., 2005, 37, 389. doi: 10.1016/j.jpba.2004.10.022 